\title{
UM OLHAR TERRITORIAL PARA O MERCADO DE TRABALHO NO BRASIL (2002-2018) $)^{1,2}$
}

\author{
Fernando Cézar de Macedo 3
}

Leonardo Rodrigues Porto ${ }^{4}$

\section{APRESENTAÇÃO}

O mercado de trabalho no Brasil reverteu, no início do século XXI, a tendência de baixo desempenho da década de 1990. O crescimento econômico, puxado pelo aumento da demanda internacional de commodities e a elevação de seus preços, até a crise mundial de 2007 e as políticas anticíclicas praticadas pós-2008 mantiveram o crescimento da economia brasileira e a continuaçáo do aquecimento do mercado de trabalho. Este se beneficiou, também, de açóes explícitas de estímulo à demanda agregada promovidas pelo governo federal em decorrência das condiçôes macroeconômicas mais favoráveis na primeira década deste século, em comparação aos anos 1990. Mesmo após a deflagração da crise mundial, continuaria crescendo, ainda que em ritmo menor. A partir de 2014, no entanto, observa-se reversão desse quadro.

A melhora do mercado de trabalho até 2014 deu-se em consonância com a ampliação do crédito às famílias e com elevação do consumo, principalmente, nas regiôes Norte, Nordeste e Centro-Oeste do país, em decorrência do crescimento mais elevado da renda regional vis-à-vis ao do Sul e Sudeste. ${ }^{5}$

Os investimentos públicos tiveram importância macroeconômica por elevarem a formação bruta de capital fixo (FBCF), mas, também, regional, pois as participaçóes das regióes Norte, Nordeste e Centro-Oeste na carteira de investimentos do Programa de

1. DOI: http://dx.doi.org/10.38116/brua24art3

2. Este texto é um resumo do trabalho desenvolvido para o Projeto Diagnóstico da Situação Recente da Questão Regional Brasileira, coordenado pela Diretoria de Estudos e Políticas Regionais, Urbanas e Ambientais (Dirur) do Ipea no âmbito do Acordo de Cooperação Técnica (ACT)/Ipea/Ministério do Desenvolvimento Regional (MDR) patrocinado pela Secretaria Nacional de Desenvolvimento Regional e Urbano do MDR.

3. Pesquisador do Programa de Pesquisa para o Desenvolvimento Nacional (PNPD) na Dirur/lpea; professor do Instituto de Economia da Universidade Estadual de Campinas (IE/Unicamp); pesquisador do Centros de Estudos do Desenvolvimento Econômico (CEDE).E-mail:<fcmacedo@unicamp.br>.

4. Mestre em Desenvolvimento Econômico pelo IE/Unicamp; doutorando pesquisador do CEDE.E-mail: <Inrdporto@gmail.com>. 5.0 rendimento médio por habitante, entre 2005 e 2014, cresceu nas regiões Norte, Nordeste e Centro-Oeste, respectivamente, $48,2 \%, 51,1 \%$ e $57,2 \%$, enquanto Sudeste $(+41,8 \%)$ e Sul $(+48,0 \%)$ ficaram abaixo. Entre 2014 e 2018 , a situação se inverte, com as três primeiras, apresentando perda de rendimento média mais acentuada que as demais: Norte $(-3,4 \%)$, Nordeste $(-7,7 \%)$, Sudeste $(-1,8 \%)$, Sul $(-1,5 \%)$ e Centro-Oeste $(-3,5 \%)$. 
Aceleração do Crescimento (PAC) superaram suas participaçóes no produto interno bruto (PIB) brasileiro, impactando mais favoravelmente o mercado de trabalho delas. Portanto, consumo e investimento contribuíram para a lenta, porém contínua, desconcentração regional do emprego e do PIB que se verifica neste século XXI. Entre 2002 e 2014, em pontos percentuais (p.p.), Norte (+0,6 p.p.), Nordeste ( $+0,8$ p.p.) e Centro-Oeste ( $+0,8$ p.p.) ganharam participação no PIB, assim como Sul (+0,2 p.p.), sendo Sudeste o único perdedor (-2,4 p.p.).

Essa desconcentração regional apresentou caráter positivo porque ocorreu em situação de crescimento econômico: de 3,4\% ao ano (a.a.) para o Brasil entre 2002 e 2014. Apesar de a desconcentração continuar entre 2014 e 2017 - com ganhos para Norte (+0,6 p.p.), Nordeste (+0,5 p.p.) e Centro-Oeste (+0,6 p.p.) - ela apresentou caráter espúrio, ou meramente estatístico, pois ocorreu em contexto de recessão (-1,9\% a.a.). Ou seja, as regióes que são prioritárias na política regional aumentaram sua participação por decrescerem menos que a média brasileira, especialmente o Sudeste, e não pelo desempenho econômico favorável.

Este texto analisa a dinâmica regional do mercado de trabalho formal no país entre 2002 e 2018, a partir do cenário esboçado. Ele considera dois momentos: o primeiro, até 2014, se caracterizou pelo crescimento econômico e elevação dos postos de trabalho; o segundo, entre 2015 e 2018 e que se prolonga até os dias de hoje, foi marcado por recessão e aumento do desemprego. No primeiro, a ampliação dos postos de trabalho, a queda do desemprego, o aumento da formalização e a ampliação do poder de compra da força de trabalho pelo crescimento real do salário mínimo repercutiram regionalmente de forma diferenciada, com ganhos para todas as regióes, porém maiores para o Norte, Nordeste e Centro-Oeste. Já no período 2015-2018, os efeitos recessivos sobre o mercado de trabalho foram generalizados, afetando todos os setores e em todas as regiôes. Registrou-se queda brusca do número de empregos formais, de modo que o processo de desconcentraçáo dos postos de trabalho resultou dos efeitos mais acentuados da crise nas áreas de maior adensamento econômico.

\section{COMPORTAMENTO GERAL DO MERCADO DE TRABALHO}

Um primeiro aspecto a se considerar é a queda da taxa de desocupação (ou de desemprego) entre os anos de 2001 (era de 9,4\%) e 2013 (6,2\%), embora a partir de 2014 (6,9\%) observe-se retomada de seu crescimento, que continuou em 2015 (9,6\%). Importante destacar que esse comportamento foi generalizado para todas as cinco macrorregióes, mas com especificidades. As maiores quedas nessas taxas ocorreram no Sudeste e no Sul, entre os anos de 2001 e 2013. O Nordeste apresentou redução do desemprego, mas em ritmo menor que o do país: até 2007, sua taxa de desemprego estava abaixo da média brasileira e, nos anos seguintes, ela fica acima da média nacional. Em 2004, ${ }^{6} 2013$ e 2015, as taxas de desocupação das regióes foram respectivamente: Norte $(6,9 \%, 7,3 \%$ e $8,8 \%)$, Nordeste $(9,0 \%, 7,9 \%$ e $10,1 \%)$, Sudeste $(10,5 \%, 6,6 \%$ e $10,8 \%)$, Sul $(5,7 \%, 4,0 \%$ e $6,9 \%)$ e Centro-Oeste $(8,1 \%, 5,8 \%$ e $7,7 \%)$. Apenas esta última, sustentada por sua economia de exportaçáo, apresentava taxa de desemprego menor em 2015 comparativamente a 2004.

A redução do desemprego foi acompanhada por uma melhoria na condição ocupacional. Segundo os dados da Pesquisa Nacional por Amostra Domiciliar (PNAD), a participação da força de trabalho com carteira assinada no Brasil passou de 29,3\% do total das pessoas com mais de dez anos ocupadas em 2002 para 39,8\% em 2013. Ao longo de todo esse

6. Considera-se 2004 (e não 2001) porque a partir dele incorpora-se o Norte rural. 
período, sua participaçáo foi crescente, porém, em 2014 (com 39,1\%) e em 2015 (38,6\%) observa-se seu declínio, reflexo da crise econômica.

Esse movimento foi generalizado para todo o país. As regióes Norte e Nordeste continuaram com a menor participação dos trabalhadores nessa categoria em suas estruturas ocupacionais. Na primeira, o peso dos trabalhadores com carteira assinada no total das ocupaçóes passou de 17,6\% em 2004 para 24,7\% em 2013. No Nordeste, esses números foram 16,4\% (ano de 2002) e 26,0\% (2013). Seus níveis estiveram bem abaixo das participaçóes do Sudeste (37,5\% e 48,4\%, respectivamente); Sul (33,0\% e 45,5\%) e Centro-Oeste (27,7\% e 41,0\%). Em todas elas, as participaçôes apresentaram quedas em 2014 e 2015, com exceçóes do Norte e Nordeste que ainda apresentaram ligeira ampliação em 2014.

A queda da participação dos trabalhadores sem remuneração no total foi significativa, sobretudo no Nordeste, que declinou de 13,4\%, em 2002, para 3,6\% em 2013. Ali, mais de dois milhóes de trabalhadores saíram da condição de não remunerados entre esses dois anos assinalados. Entretanto, esse movimento ocorreu generalizadamente em todas as regióes: no Norte passou de $11,5 \%$ para 5,7\%; no Sudeste de 3,3\% para 1,2\%; no Sul de 9,7\% para 3,2\%; e no Centro-Oeste de 4,6\% para 1,3\%. ${ }^{8}$ Apesar dessa evolução, as regióes Norte e Nordeste possuíam 55,4\% do total dos trabalhadores sem remuneração do país em 2013 (em 2004 esse valor era de 60,5\%).

No pós-2003, o emprego formal cresceu a taxas mais elevadas do que o crescimento da economia brasileira e do próprio ritmo de geração de empregos, medido pela evolução de pessoas ocupadas (POs). Isso ocorreu em todas as grandes regióes (tabela 1), o que foi a principal novidade no mercado de trabalho brasileiro. É nesse sentido que Baltar et al. (2010) e Baltar (2015) referem-se a um crescimento desproporcional do emprego formal, até 2014.

$\mathrm{O}$ aumento mais acelerado dos vínculos formais vis-à-vis o aumento da PO representou melhora na qualidade do emprego. Em parte, também responde pela elevação da participação da renda do trabalho na demanda agregada. Ademais, a maior formalizaçáo habilitou os trabalhadores a terem acesso mais fácil ao crédito e às linhas de financiamento do sistema bancário comercial. Isso ajuda a explicar por que no período o consumo teve crescimento maior nas regiōes Norte, Nordeste e Centro-Oeste.

TABELA 1

Taxas de crescimento médio anual do PIB, da PO e do emprego formal (2003-2014)

(Em \%)

\begin{tabular}{llcc}
\hline Região & PIB & PO & Emprego formal \\
\hline Norte & 4,8 & 5,5 & 6,7 \\
Nordeste & 4,1 & 1,3 & 5,4 \\
Sudeste & 3,5 & 1,9 & 4,4 \\
Sul & 3,0 & 1,3 & 4,5 \\
Centro-Oeste & 4,7 & 2,7 & 5,4 \\
\hline
\end{tabular}

Fonte: IBGE; PNAD; Sistema de Contas Nacionais do Instituto Brasileiro de Geografia e Estatística (SCN/IBGE); Ministério da Economia; Relação Anual de Informações Sociais (Rais).

É importante registrar que o estoque de PO no Brasil aumentou em 18,7 milhóes, entre 2003 e 2014, enquanto o emprego formal cresceu num total de pouco mais de

7. No Norte esses dados estão referenciados para 2004 e 2013.

8. Dados referentes a 2002 e 2013, menos para o Norte, que se referem a 2004 e 2013. 
20 milhões. Isso indica que o crescimento dos trabalhadores formais não derivou apenas do desempenho econômico, mas também pelas razôes apontadas por Krein e Manzano (2014): o aprimoramento do aparato regulatório; a consolidação das instituiçôes e do marco legal definido na Constituição de 1988; as novas perspectivas e programas das instituiçôes públicas na área do trabalho; políticas de incentivo à formalização e simplificação promovidas pelo Estado; e ampliaçáo do poder de barganha dos sindicatos e trabalhadores.

Em termos regionais, Sul e Nordeste apresentaram maior relação entre empregos formais gerados e novas POs. A regiáo Sul ampliou o número de POs em 2 milhóes, enquanto o número de registros Rais cresceu em 3,3 milhôes. Já para o Nordeste, os números foram de 3,3 milhóes e 4 milhóes, respectivamente. Por sua vez, a região Sudeste teve crescimento de 7,8 milhóes (PO) e 9,4 milhóes (vínculos ativos) e o Centro-Oeste teve crescimento aproximado das duas cifras, sendo 2 milhôes de PO e 1,9 milhão de empregos registrados na Rais. Apenas a regiáo Norte teve crescimento absoluto de empregos Rais (1,4 milhão de novos vínculos) em ritmo menor do que o crescimento da $\mathrm{PO}$ (3,5 milhóes). ${ }^{9}$ Essa maior formalização apresentou características espaciais desconcentradoras, como se verá a seguir.

\section{DO CRESCIMENTO ACELERADO À RETRAÇÃO DO MERCADO DE TRABALHO}

O período subsequente, de 2015 a 2018, inaugura nova fase, ainda em processo, no qual se verifica forte reversão do quadro anterior, com queda dos indicadores de emprego formal, sem que ainda se tenha apontado indícios de retomada. Inclusive, a situação se agravou com a pandemia da Covid-19 em 2020.

Verificou-se queda brusca do número de empregos formais em 2015 e 2016 no Brasil, levando as cifras para os níveis do início da década. Em 2017 e 2018, o mercado de trabalho formal estabilizou-se, sem quedas abruptas, mas sem retomar os padróes anteriores. Em 2018, o estoque de empregos formais no país era de 46,6 milhóes de vínculos ativos, algo 5,9\% menor do que era em 2014. A queda chegou a ser de $-7,1 \%$, em 2016, equivalente a uma perda de 3,5 milhóes de empregos formais, entre 2014 e 2016, após dois anos de aumento expressivo das demissóes e de elevaçáo do desemprego no país.

Em termos regionais, Norte, Nordeste e Centro-Oeste apresentaram maior expansão de empregos formais no período 2002-2014, contribuindo para maior desconcentração. Após 2015, essa relaçáo começa a se alterar, conforme os diferentes impactos da crise econômica entre as regiōes. A regiáo Norte, que havia apresentado o maior ritmo de expansão no período 2002-2014, reduziu seu estoque de empregos formais em -4,8\%, entre 2014 e 2018, ou seja, uma perda de 134 mil postos de trabalho. O Nordeste, por sua vez, teve perda acumulada de 485 mil postos de trabalho, nesse mesmo período, uma redução de $-5,3 \%$ dos vínculos ativos. Essa perda chegou a ser de $-7,6 \%$ em 2016, em relação a 2014 . Ou seja, a região sofreu os efeitos imediatos da crise econômica sobre o mercado de trabalho de maneira mais intensa que a média do país, num primeiro momento (2015-2016), mas se recuperando nos anos subsequentes (2017-2018), ficando com o resultado relativo acumulado mais favorável do que o Brasil.

A região Centro-Oeste apresentou maiores oscilaçóes no período 2015-2018. Em relação a 2014, que foi o ápice do crescimento dos empregos formais, a região perdeu $115 \mathrm{mil}$ postos de trabalho, sendo a menor redução do país até 2018, em termos relativos (-2,7\%).

9. Em termos relativos, o ritmo de crescimento do emprego formal da região Norte ocorreu de forma mais acelerada que 0 de sua população ocupada, conforme demonstrado na tabela 1. 
Isso significa que os impactos da crise sobre o mercado de trabalho foram menores ali. A região foi a única que voltou a apresentar redução de seus postos de trabalho em 2018, após crescimento em 2017. O dado reflete, também, a dinâmica econômica dessa região, vinculada aos movimentos da demanda internacional de commodities.

As regiôes Sul e Sudeste apresentaram os menores ritmos de expansão da geração de empregos formais, entre 2002 e 2014, com a segunda apresentando as menores taxas de crescimento. Já no período subsequente (2015-2018), foi a regiáo Sudeste que apresentou o pior desempenho relativo entre as cinco macrorregióes brasileiras. Após 2014, a região perdeu 1,9 milhão de postos de trabalho, uma queda relativa de $-7,6 \%$. De igual modo, no subperíodo 2017-2018, o Sudeste foi a regiáo com a pior capacidade de recuperação, cuja retomada foi de apenas 0,2 p.p. dos empregos perdidos em 2015-2016.

A regiâo Sul teve perda acumulada de 325 mil vínculos ativos nesse período de crise, ou sejam uma queda de $-3,8 \%$. No entanto, seu desempenho só não é mais favorável do que o verificado na regiáo Centro-Oeste. O principal destaque é o do subperíodo 2017-2018, quando a regiáo recuperou boa parte dos empregos perdidos no subperíodo 2015-2016.

A tabela 2 apresenta as taxas de crescimento do emprego formal no Brasil e suas regióes, assim como sua distribuição regional e nos diferentes períodos analisados. Entre 2002-2018, o país elevou o número de postos de trabalho formais a uma taxa média anual de crescimento de 3,1\%. No período 2002-2014, esse crescimento havia sido de 4,7\% a.a., enquanto no período subsequente (2015-2018), a queda foi de 1,0\% a.a.

TABELA 2

Taxas médias de crescimento anual do número de empregos formais e participação relativa (2002-2018) (Em \%)

\begin{tabular}{|c|c|c|c|c|c|c|}
\hline \multirow{2}{*}{ Níveis territoriais } & \multicolumn{3}{|c|}{ Taxas médias anuais de crescimento } & \multicolumn{3}{|c|}{ Participação relativa } \\
\hline & $2002-2018$ & $2002-2014$ & $2015-2018$ & 2002 & 2014 & 2018 \\
\hline Brasil & 3,1 & 4,7 & $-1,0$ & 100,0 & 100,0 & 100,0 \\
\hline Centro-Oeste & 3,7 & 5,3 & $-0,3$ & 8,1 & 8,7 & 9,0 \\
\hline Nordeste & 3,7 & 5,4 & $-1,0$ & 16,9 & 18,4 & 18,5 \\
\hline Norte & 4,6 & 6,6 & $-0,7$ & 4,5 & 5,7 & 5,7 \\
\hline Sudeste & 2,6 & 4,2 & $-1,4$ & 52,7 & 50,0 & 49,1 \\
\hline Sul & 3,1 & 4,4 & $-0,4$ & 17,7 & 17,2 & 17,6 \\
\hline
\end{tabular}

Fonte: Rais/Ministério da Economia.

Entre as macrorregióes brasileiras, verificou-se o aumento da participação relativa das regióes Norte, Nordeste e Centro-Oeste. O Norte elevou sua participação na distribuição dos empregos formais do país em 1,2 p.p., no período 2002-2018, passando de 4,5\% do total do país, em 2002, para 5,7\%, em 2018. No período 2015-2018, a regiáo apresentou perdas a um ritmo de $0,7 \%$ a.a., de modo que manteve a sua participação no total do país, em relação a 2014 (era de 5,7\%).

O Nordeste passou de 16,9\% do total de vínculos ativos formais do país, em 2002, para 18,4\%, em 2014 (auge do crescimento), e 18,5\% em 2018, na crise. Esse resultado reflete as quedas mais acentuadas apresentadas pela região Sudeste, verificadas no período. Com efeito, o Nordeste apresentou perdas de empregos formais a uma taxa de 1,0\% a.a., similar ao Brasil. Entre as regiōes, foi o segundo pior desempenho, ficando atrás apenas do Sudeste (queda de $1,4 \%$ a.a.), na qual os efeitos da crise foram mais significativos. 
O Centro-Oeste, por seu turno, continuou elevando sua participação no total nacional de empregos formais, mesmo após a crise. Ao todo, a região elevou sua participação em 0,9 p.p. entre 2002 e 2018, passando de 8,1\%, em 2002, para 8,7\%, em 2014, e 9,0\% em 2018. $\mathrm{Na}$ crise, a regiáo foi a menos afetada, com queda de 0,3\% a.a. entre 2015 e 2018.

O Sudeste apresentou desempenho relativo ainda mais sofrível. Perdeu posição no período de maior crescimento da economia (2002-2014) e continuou perdendo com a deflagraçáo da crise (2015-2018). Seu estoque de empregos formais passou de 52,7\% do total do país, em 2002, para 49,1\%, em 2018, quando era de 50,0\%, em 2014. Essa perda de 3,6 p.p. expressa a continuidade do processo de desconcentração dos empregos no país, motivada por fatores diferentes. $\mathrm{Na}$ fase de crescimento, apresentou as mais baixas taxas de expansão do emprego ( $4,2 \%$ a.a.) e, com a crise, verificaram-se as maiores quedas, em um ritmo negativo de $1,4 \%$ a.a.

Por sua vez, a região Sul voltou a recuperar participação relativa com a crise. Essa região, entre 2002 e 2014, passou de $17,7 \%$ do estoque de empregos formais do Brasil para $17,2 \%$, resultado da segunda menor taxa de expansão do período ( $4,4 \%$ a.a.). No período 2015-2018, porém, voltou a recuperar participação com $17,6 \%$ do total de vínculos ativos, em 2018. Esse resultado decorreu de um ritmo de perdas menor do que em outras regióes $(-0,4 \%$ a.a. $)$, ficando atrás apenas do Centro-Oeste.

Em termos setoriais, verificaram-se mudanças importantes na estrutura do emprego formal e sua distribuição entre as regióes. Entre 2002 e 2018, as regiōes Norte, Nordeste e Centro-Oeste ganharam participação relativa em todos os cinco grandes setores analisados. A única exceção é a perda de participação de 0,6 p.p. do Nordeste no setor agropecuário, em relação ao total dos empregos no setor, nesse período.

A região Norte se destacou positivamente com a melhora de sua participação no número de empregos formais da agropecuária, passando de 2,8\% do total de vínculos ativos nesse setor, em 2002, para 6,6\% em 2018 (elevação de 3,8 p.p.). Esse desempenho refletiu a expansão do agronegócio exportador na região que apresenta maiores índices de formalização do trabalho, em decorrência do perfil das empresas que operam no setor. Em relação a 2014, o Norte perdeu participação relativa no setor da construção civil, com queda de 1,2 p.p. nesses quatro anos, sendo o setor mais afetado na regiáo, com a crise pós-2015.

O Nordeste foi a regiấo que mais ampliou participação do emprego formal no setor de comércio (+ 2,5 p.p.) e de serviços (+ 1,6 p.p.) durante o período 2002-2018. Em relação ao comércio, passou de $14,8 \%$ do total do país, em 2002 , para $17,4 \%$, em 2014 , e $17,3 \%$, em 2018. Em serviços, as cifras foram de 18,8\%, 20,1\% e 20,4\%, respectivamente. O desempenho desses setores no Nordeste é resultado direto das políticas adotadas no período, que favoreceram a expansáo do consumo das famílias. Já durante a crise, o destaque negativo vai para a perda de participaçáo do setor da construçáo civil, com queda de 2,6 p.p. entre 2014 e 2018, repercutindo os impactos da retração de um setor tradicionalmente empregador.

A região Centro-Oeste tem destaque positivo com o aumento na participação do número de postos de trabalho da indústria (extrativa, transformação e serviços de utilidade pública) durante o período analisado. Entre 2002 e 2018, os ganhos foram de 1,9 p.p., chegando a representar 6,5\% dos empregos no setor em 2018, quando era de 4,6\%, em 2002. Em parte, esse desempenho é resultante do aumento de empregos relacionados à agroindústria. Tal se deu, também, com a expansão dos empregos formais vinculados à agropecuária da região, com ganho de 6,7 p.p. nesse período. Com efeito, a região passou a figurar com o maior 
número de postos de trabalho no setor, em 2018, superando o Nordeste e o Sul, que eram os maiores em 2002. Com a crise, a região continuou ganhando participação relativa em todos os setores analisados, destacando-se sobretudo a agropecuária.

O Sudeste perdeu participação no número de vínculos ativos em todos os cinco setores analisados, entre 2002 e 2018. A indústria perdeu participação de 3,5 p.p. nesse período; a queda na construção civil foi de 2,4 p.p.; o comércio, $-4,3$ p.p.; os serviços, -3,3 p.p.; e a agropecuária representou uma queda de 8,5 p.p., em muito influenciado pelas mudanças produtivas no cultivo da cana-de-açúcar, cada vez menos demandante de mão de obra. A regiâo continuou perdendo participação setorial dos empregos pós-2015, com o advento da crise. No entanto, houve ganhos de participação da construção civil, que recuperou 1,4 p.p. dos empregos formais, entre 2014 e 2018.

Por fim, a região Sul se destaca pela perda de participação dos empregos formais do setor agropecuário, durante todo o período analisado. Já entre os anos de 2014 e 2018, verificaram-se ganhos importantes junto à indústria (aumento de 1,0 p.p.) e à construçáo civil, com aumento de 1,9 p.p., passando de 14,2\% dos empregos, em 2014, para 16,1\%, em 2018.

Em termos gerais, é possível dizer que o período de maior crescimento econômico (2002-2014) promoveu mais amplas transformaçôes na estrutura setorial dos empregos formais entre as regiôes brasileiras. Com a crise econômica, os efeitos recessivos sobre o mercado de trabalho foram generalizados, afetando mais ou menos todos os setores por igual, em todas as regiôes. A principal exceção é o caso da construção civil, bastante afetada com a crise, levando a maior redistribuiçáo do número de postos de trabalho entre as regiôes, inclusive com a reconcentração no Sudeste.

A análise se complementa com um breve panorama do que aconteceu com o emprego formal no âmbito das microrregióes (MRGs), nesse período recente de cenário de crise econômica. Considera-se, aqui, a tipologia sub-regional da PNDR aplicada às MRGs, conforme os parâmetros atualizados por Macedo e Porto (2018). O desempenho das MRGs segundo a sua tipologia regional pode ser observado na tabela 3, para todo o período analisado (2002-2018).

\section{TABELA 3}

Taxas médias de crescimento anual do número de empregos formais e participação relativa, segundo a tipologia sub-regional da PNDR (2002-2018)

(Em \%)

\begin{tabular}{lcccccccc}
\hline \multirow{2}{*}{ Tipologia da PNDR } & \multicolumn{3}{c}{ Taxas médias anuais de crescimento } & & \multicolumn{3}{c}{ Participação relativa } \\
\cline { 2 - 3 } \cline { 7 - 8 } & $2002-2018$ & $2002-2014$ & $2015-2018$ & & 2002 & & 2014 & 2018 \\
\hline Alta renda & 2,8 & 4,4 & $-1,3$ & & 78,2 & 76,1 & 75,1 \\
Baixa renda & 4,3 & 5,6 & 0,6 & & 2,8 & 3,1 & 3,3 \\
Dinâmica & 4,4 & 6,1 & $-0,4$ & & 6,0 & 7,0 & 7,2 \\
Estagnada & 3,7 & 5,1 & $-0,3$ & & 13,1 & 13,8 & 14,3 \\
\hline
\end{tabular}

Fonte: RAIS/Ministério da Economia.

Em 2018, as MRGs de alta renda concentravam 75\% dos empregos formais do país, sendo a única que perdeu participação relativa durante o período analisado. Esse grupo apresentou a menor taxa de crescimento dos postos de trabalho, em todo o período, com ritmo menos acelerado na fase de maior crescimento - 4,4\% a.a. entre 2002 e 2014 - e com a maior queda no período da crise, cuja redução foi de -1,3\% a.a., entre 2015 e 2018. 
Em 2018, as MRGs de alta renda respondiam por 35 milhóes dos vínculos ativos de emprego formal do país.

As MRGs de baixa renda, que foram alvos prioritários de políticas públicas, elevaram a sua participação no número de empregos formais em 0,6 p.p., entre 2002 e 2018, sendo que 0,3 p.p. foram obtidos no período da crise econômica. Esse foi o único grupo a apresentar crescimento positivo, entre 2015 e 2018. Cresceu à taxa de 0,6\% a.a., nesse período, tendo apresentado cifra negativa apenas em 2016, quando perdeu mais de 90 mil postos de trabalho, em relação a 2015. Nos demais anos, as cifras foram de: aumento de apenas 284 postos de trabalho, em 2015; crescimento de 85 mil, em 2017; e 36 mil, em 2018. Nesse último ano, seu estoque de empregos formais foi de 1,5 milhão de vínculos ativos.

No caso das MRGs dinâmicas, houve redução do número de vínculos ativos formais, entre 2015 e 2018, a uma taxa de $-0,4 \%$ a.a. Foi um dos piores resultados entre os quatro grupos, demonstrando freio justamente nas áreas que lideravam o crescimento no período anterior. Entre 2002 e 2014, as MRGs dinâmicas cresceram à taxa de 6,1\% a.a., o que elevou a sua participação relativa no total do país, passando de 6,0\%, em 2002, para 7,0\%, em 2014, e 7,2\%, em 2018. Esse ganho de participaçáo em 2018 decorre, sobretudo, do péssimo desempenho das MRGs de alta renda.

As MRGs estagnadas, por sua vez, apresentaram crescimento de 5,1\% a.a. entre $2002 \mathrm{e}$ 2014, e queda de -0,3\% a.a., no período subsequente (2015-2018). Com isso, elevou a sua participação no total de empregos formais do país, durante o período analisado. Em 2002, respondia por 13,1\% dos postos de trabalho, passando para 14,3\%, em 2018.

O desempenho desses quatro grupos reforça o padrão verificado em outros níveis territoriais de observaçáo para esse período recente. Qual seja, no período 2015-2018, o processo de desconcentração dos postos de trabalho decorreu, sobretudo, dos impactos da crise econômica sobre as áreas de maior adensamento econômico do país. Assim, há um processo diferenciado em relação ao período anterior, quando a redistribuição dos vínculos ativos acompanhava o processo de desconcentração econômica regional promovida pelo bom desempenho das regiôes Norte, Nordeste e Centro-Oeste.

\section{CONSIDERAÇÕES FINAIS}

O texto realizou uma análise da evolução regional do emprego formal no país, tomando como referenciais os períodos 2002-2014 e 2015-2018. Verificou-se uma fase positiva de expansão do mercado de trabalho formal no Brasil, no período 2002-2014, com o emprego crescendo a taxas mais elevadas que o crescimento da economia brasileira, tendo sido um fenômeno comum a todas as regiôes. Após 2014, o mercado de trabalho brasileiro apresentou forte reversão, em relação ao período anterior. Entre os anos de 2015 e 2018, verificou-se a queda dos indicadores do emprego formal, em decorrência da grave crise econômica e política no país, sem que ainda exista indícios de retomada.

Em relação aos quatro grupos sub-regionais definidos pela PNDR, seu desempenho reforça o padrão verificado também em outras escalas de análise, durante esse período mais recente. Entre 2015 e 2018, o processo de desconcentração dos postos de trabalho decorreu, sobretudo, dos impactos da crise econômica sobre as áreas de maior adensamento econômico do país. Dessa maneira, o texto evidenciou como os mercados de trabalho regionais puderam reagir aos ciclos econômicos recentes. 


\section{REFERÊNCIAS}

BALTAR, P. Crescimento da economia e mercado de trabalho no Brasil. Rio de Janeiro: Ipea, 2015. (Texto para Discussão, n. 2036).

BALTAR, P. E. A. et al. Trabalho no governo Lula: uma reflexão sobre a recente experiência brasileira. Global Labour University, n. 9, May 2010.

KREIN, J. D.; MANZANO, M. P. Notas sobre a formalizaçáo: estudo de caso Brasil. Brasília: OIT, 2014. Disponível em: <http:/www.ilo.org/wcmsp5/groups/public/---americas/---ro-lima/ documents/publication/wcms_245624.pdf>. Acesso em: 10 jul. 2017.

MACEDO, F. C.; PORTO, L. R. Proposta de atualizaçáo das tipologias da PNDR: nota metodológica e mapas de referência. Brasília: Ipea, 2018. (Texto para Discussão, n. 2414). 
